Research Article

\title{
Study on Crystallization and Magnetic Property Deviation of Ni-Zn-Cu Ferrite Depending on the State of the Starting Material in the Annealing Process
}

\author{
Su-won Yang, Kwang-pil Jeong, and Jeong-gon Kim \\ Department of Material Science \& Engineering, Incheon National University, 119 Academi-ro, Yeonsu-gu, Incheon, \\ Republic of Korea \\ Correspondence should be addressed to Jeong-gon Kim; jyj309@inu.ac.kr
}

Received 25 August 2017; Revised 31 October 2017; Accepted 7 November 2017; Published 17 December 2017

Academic Editor: Pavel Lejcek

Copyright ( 2017 Su-won Yang et al. This is an open access article distributed under the Creative Commons Attribution License, which permits unrestricted use, distribution, and reproduction in any medium, provided the original work is properly cited.

\begin{abstract}
The spinel structure of the nanosize powder $\left(\mathrm{Ni}_{0.3} \mathrm{Zn}_{0.3} \mathrm{Cu}_{0.4} \mathrm{Fe}_{2} \mathrm{O}_{4}\right)$ substituted by $\mathrm{Ni}, \mathrm{Zn}$, and $\mathrm{Cu}$ was fabricated by the sol-gel process. Changes in weight, crystal formation, and magnetic properties were observed by XRD, TG-DTA, VSM in the annealing process of the sol and gel. The saturation magnetization of the sol showed $54.8-58.6 \mathrm{emu} / \mathrm{g}$ at $500-800^{\circ} \mathrm{C}$, and the gel showed $52.3-56.8 \mathrm{emu} / \mathrm{g}$ at $600-800^{\circ} \mathrm{C}$. The coercive force of the sol decreased in the range $-136 \mathrm{Oe}$ to $-11.4 \mathrm{Oe}$ at $500-800^{\circ} \mathrm{C}$, and the gel decreased in the range $-95 \mathrm{Oe}$ to $-44 \mathrm{Oe}$ at $600-800^{\circ} \mathrm{C}$. Therefore, the deviation of the annealing temperature of the nanopowder fabricated in the sol process and the gel process was about $100^{\circ} \mathrm{C}$.
\end{abstract}

\section{Introduction}

Data usage has increased rapidly in the development of wireless communication and electronic industry. To transmit a large amount of data, gigahertz frequency is used. Therefore, wave interference of the gigahertz frequency occurs frequently [1]. Thus, the study of the wave absorber is continuously carried out by a lot of researchers [2, 3]. Ferrite is the most widely used wave absorber material. Ferrites form various structures such as iron oxides, the spinel, the garnet, and the hexagonal [4]. The hexagonal ferrite could be classified into M-type, U-type, X-type, and Y-type by an additional atom and by stacking method [4]. It can be confirmed from the previous studies that the hexagonal ferrite can absorb in the frequency range of several $\mathrm{MHz}$ to tens of $\mathrm{GHz}$ depending on the type [5]. The spinel structure of the nanosize powder substituted by $\mathrm{Ni}, \mathrm{Zn}$, and $\mathrm{Cu}$ was fabricated by the sol-gel process. Elements such as $\mathrm{Ni}, \mathrm{Zn}, \mathrm{Cu}$, and $\mathrm{Mn}$ can be substituted at the tetrahedral site and octahedral site in the $\mathrm{Fe}_{2} \mathrm{O}_{4}$ ferrite [6]. And the magnetic properties of the spinel ferrite could be changed by substituted elements [6]. The other factors are crystal size and uniformity of spinel ferrite. Also, according to the previous studies, the ferrite is confirmed by wave absorption in the frequency range of the tens of $\mathrm{MHz}$ to several hundred $\mathrm{MHz}$ ranges [7]. However, the other study confirmed that the nanometer size crystal of the spinel ferrite could absorb waves in the gigahertz frequency region [3]. In this study, the nanopowder of spinel ferrite substituted by $\mathrm{Ni}, \mathrm{Zn}$, and $\mathrm{Cu}$ was synthesized by the sol-gel process. $\mathrm{Zn}$ and $\mathrm{Cu}$ are mainly substituted at the A-site in the tetrahedral, and $\mathrm{Ni}$ is mainly substituted at the B-site in the octahedral. The substituted $\mathrm{Ni}, \mathrm{Zn}$, and $\mathrm{Cu}$ change the saturation magnetization value of ferrite. It is because that $\mathrm{Ni}^{2+}, \mathrm{Zn}^{2+}$, and $\mathrm{Cu}^{2+}$ ions reveal the different net moments from $\mathrm{Fe}^{2+}$ ion. Differences in properties were mentioned in our previous paper in detail [8]. The sol-gel process has advantages. It is simple and can fabricate a high-purity powder. In a typical sol-gel process, the sol was dried to form the gel, and then the nanopowder was obtained after the annealing process of the gel. In this study, we confirmed the influence on the spinel crystal formation by 
annealing the sol and the gel, respectively. And, the deviation in the process of crystal formation and magnetic properties of spinel ferrite was analyzed.

\section{Experimental}

In this study, $\mathrm{Ni}_{0.3} \mathrm{Zn}_{0.3} \mathrm{Cu}_{0.4} \mathrm{Fe}_{2} \mathrm{O}_{4}$ (NZCF04) was synthesized by sol-gel process. Iron nitrate, nickel acetate, zinc acetate, copper acetate, citric acid, ethylene glycol, and DI water were used as starting materials. The starting materials were mixed by stoichiometry, and citric acid and ethylene glycol were added as the total mole of the starting materials. The mixture was dissolved with DI water. At this time, DI water was added to the minimum amount so that the NZCF04 mixture could be dissolved. The hydrogen ion concentration of the NZCF04 mixture was adjusted to $\mathrm{pH} 6$ by adding ammonia solution. A NZCF04 sol was prepared by heating the NZCF0 4 mixture at $85^{\circ} \mathrm{C}$ for 8 hours. The generated vapor was cooled and refluxed to keep the concentration of the mixture constant. And the NZCF04 gel was prepared by heating the NZCF04 sol on a hotplate at $100^{\circ} \mathrm{C}$ for 4 hours. To convert the fabricated NZCF04 sol and gel into nanopowder, annealing process was performed at $400-800^{\circ} \mathrm{C}$ for 3 hours. TG-DTA was measured to confirm the phase change of NZCF04 sol and gel with temperature. The heating rate of TG-DTA was set as $5^{\circ} \mathrm{C} / \mathrm{min}$, which was the annealing heating rate. Lattice parameter and crystal size of nanopowder fabricated with NZCF04 sol and gel were measured by XRD (Rigaku, SmartLab, Cu Ka). The size and shape of the nanocrystals were analyzed by SEM (JEOL, JSM-7800F). The saturation magnetization, coercive force, and initial permeability of nanopowders fabricated with NZCF04 sol and gel were analyzed by VSM (Quantum Design, VersaLab VSM, $\pm 3,000$ Oe).

\section{Results and Discussion}

TG-DTA analysis was performed to confirm the phase change of the sol and the gel with temperature. The results of TG-DTA analysis are displayed in Figure 1. In the sol and the gel of NZCF04, the weight was reduced by evaporation of water at less than $200^{\circ} \mathrm{C}$. The weight of the NZCF04 sol was reduced rapidly under $200^{\circ} \mathrm{C}$, and the weight of NZCF0 4 gel was reduced rapidly under $100^{\circ} \mathrm{C}$ to $200^{\circ} \mathrm{C}$. The sol and the gel showed endothermal reaction simultaneously at $200^{\circ} \mathrm{C}$. This confirmed that the residue of the sol-gel process vaporized up to $200^{\circ} \mathrm{C}$ and endothermic reaction by crystallization occurred. It was confirmed that the gel showed rapid endothermic reaction at $200^{\circ} \mathrm{C}$, and the sol showed it at $200-350^{\circ} \mathrm{C}$ range. The sol and the gel showed weight reduction at $320^{\circ} \mathrm{C}$ to $550^{\circ} \mathrm{C}$. The results of the TG-DTA analysis showed that the inflection point of heat flow of the sol and the gel was at $320^{\circ} \mathrm{C}$ and $350^{\circ} \mathrm{C}$, respectively. These inflection points of heat flow indicate that NZCF04 initial crystals were formed at these temperature regions. For the gel, inflection points were found in the weight ratio curve and the heat flow curve in the region of $550^{\circ} \mathrm{C}$ to $650^{\circ} \mathrm{C}$, and this phenomenon was estimated to be caused by the phase change of the spinel crystal. The phase change of the sol is

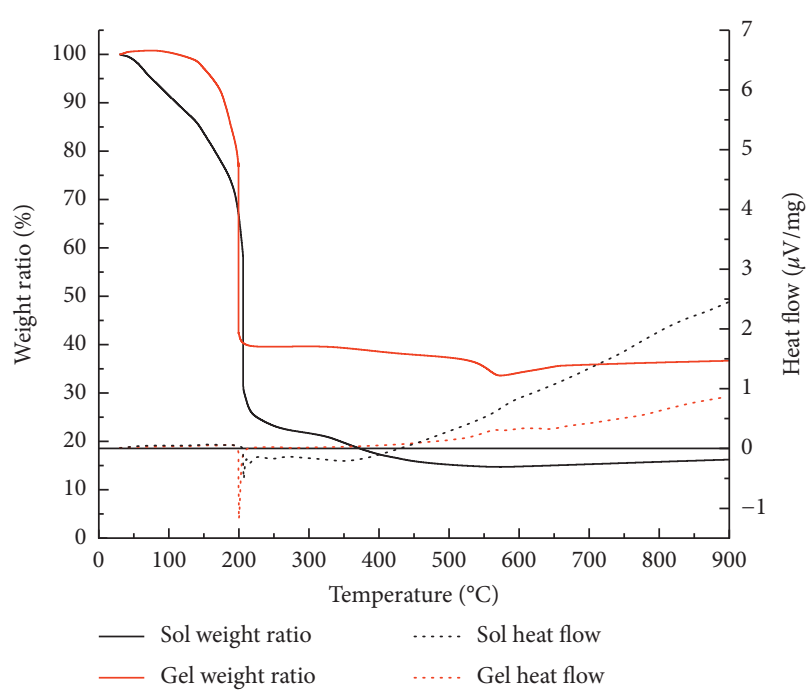

FIGURE 1: TG-DTA result: weight ratio and heat flow of the sol and gel.

estimated at $330^{\circ} \mathrm{C}$ to $550^{\circ} \mathrm{C}$ range. The temperature range from $700^{\circ} \mathrm{C}$ to $900^{\circ} \mathrm{C}$ was the grain growth sector, in which the sol and the gel showed similar weight ratio change. However, the sol showed more rapid change in heat flow than the gel. This means that the sol requires more energy for crystal growth.

The XRD pattern of the sol and the gel is displayed in Figure 2. The pattern of the sol and the gel showed broad peaks at $400^{\circ} \mathrm{C}$. It means the crystal size of $400^{\circ} \mathrm{C}$ annealing process was below a few nanometer. And It could be confirmed that this annealing process was the spinel crystal generating stage, compared with TG-DTA result.

The sol and the gel showed sharp peaks at over $500^{\circ} \mathrm{C}$, and thus it was confirmed that spinel crystals were formed. The inflection point of the gel at $550-600^{\circ} \mathrm{C}$ in Figure 1 could be confirmed in the XRD pattern at $600^{\circ} \mathrm{C}$. It can be seen that the intensity of the XRD main peak (311) at $600^{\circ} \mathrm{C}$ is reduced, and the FWHM is increased above $500^{\circ} \mathrm{C}$. The FWHM of the gel was 0.267 and 0.299 , respectively, at each temperature. It means that the crystal structure at $600^{\circ} \mathrm{C}$ was more irregular than at $500^{\circ} \mathrm{C}$. That is, it could be estimated that a change has occurred in the spinel crystal structure.

The change in the crystal size with annealing temperature is displayed in Figure 3. It could confirm that the crystal size of the sol and gel increases with increasing annealing temperature. It can be seen that the initial crystal size of the sol and the gel was $19 \mathrm{~nm}$ and $36 \mathrm{~nm}$ at $400^{\circ} \mathrm{C}$, respectively. The crystal growth has progressed at $800^{\circ} \mathrm{C}$, and the crystal size of the sol and the gel was $102 \mathrm{~nm}$ and $94 \mathrm{~nm}$, respectively. The crystal size was calculated by the following Debye-Scherrer equation:

$$
D_{p}=\frac{0.94 \lambda}{\beta \cos \theta},
$$

where $D_{p}=$ average crystallite size, $\beta=$ line broadening in radians (FWHM), $\theta=$ Bragg angle, and $\lambda=\mathrm{X}$-ray wavelength (1.54 $\AA$ ).

The main factor of the crystal size in (1) is $\beta$ (FWHM). Looking at FWHM of the sol and the gel, it can be seen that 


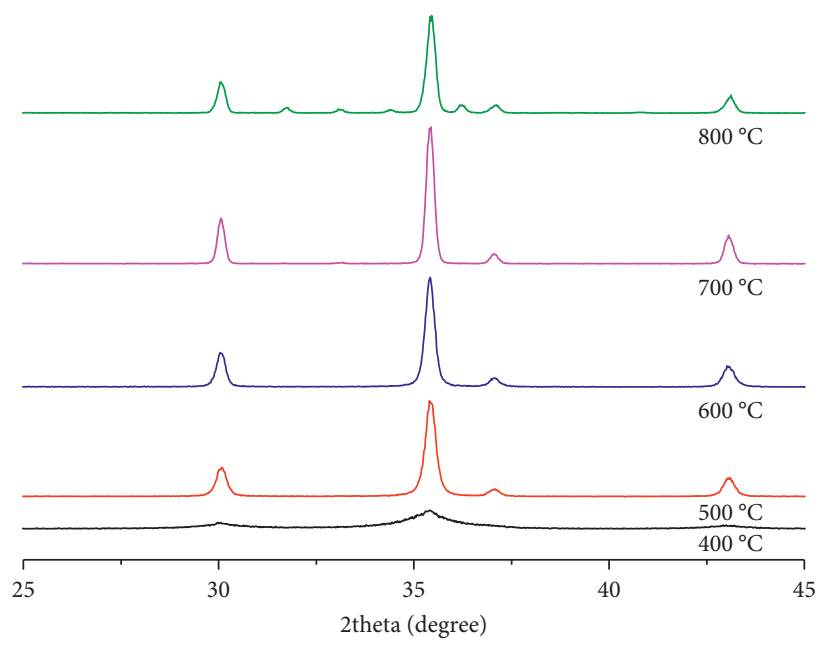

(a)

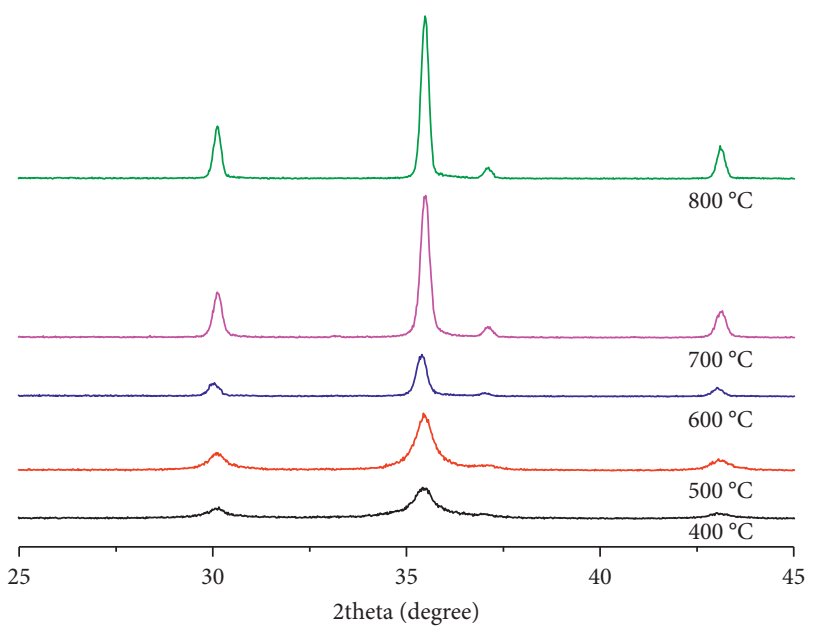

(b)

Figure 2: XRD pattern of NZCF04: (a) NZCF04 sol and (b) NZCF04 gel.

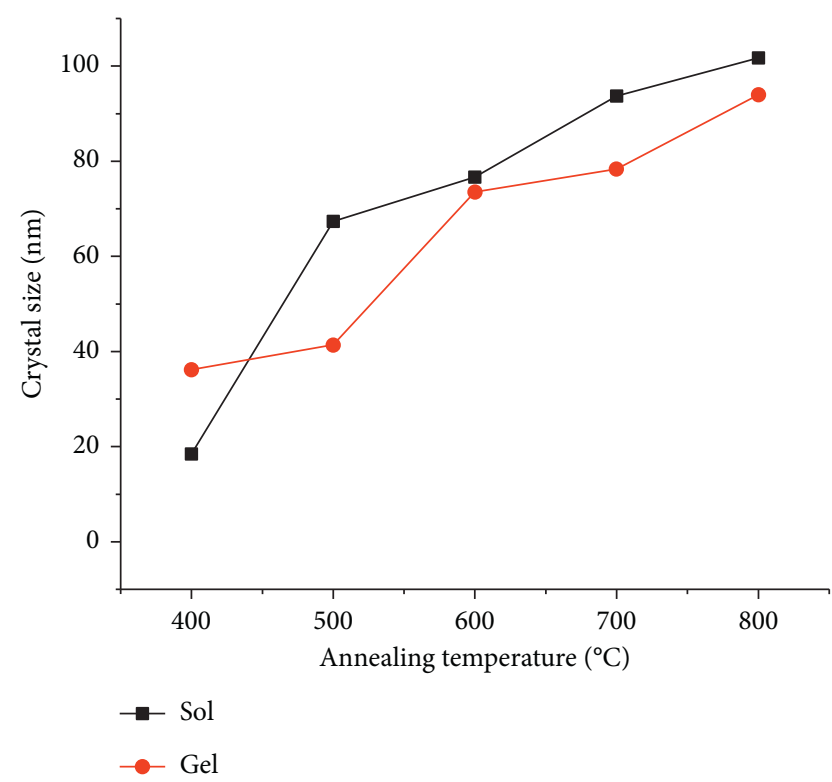

FIGURE 3: NZCF04 crystal size of the sol and the gel with annealing temperature.

the FWHM of the sol decreased from 1.08 to 0.19 and that of the gel decreased from 0.59 to 0.2 . It confirms that the decrease in FWHM is the main factor for crystal growth.

The SEM image of the sol and the gel is displayed in Figure 4. Calculated initial crystal sizes of the sol and the gel annealed at $400^{\circ} \mathrm{C}$ were $19 \mathrm{~nm}$ and $36 \mathrm{~nm}$, respectively. It could also be confirmed in Figures 4(a) and 4 (b). In Figure 4(c), the sol annealed at $800^{\circ} \mathrm{C}$, and the crystal size was seen over $100 \mathrm{~nm}$. Thus, it confirmed that the crystal has grown rapidly at this temperature. Then, it can be confirmed that the sol showed more endothermic reactions than the gel for crystal growth.

The initial permeability is displayed in Figure 5. It shows that the initial permeability of the sol and the gel increased with increasing annealing temperature. The initial permeability of the sol increased from 0.033 to 0.096 and the gel from 0.042 to 0.090 . The sol showed a continuous increase in proportion to the annealing temperature, and the gel showed rapid increase from 0.055 to 0.088 after $700^{\circ} \mathrm{C}$. The reason was estimated to be due to the rapid growth of the crystal. This could be confirmed from the $700^{\circ} \mathrm{C}$ XRD pattern and the result of TG-DTA of the gel.

It could be confirmed that the initial permeability was related to the crystal size and uniformity.

The coercive force and the saturation magnetization of the sol and the gel are displayed in Figure 6. The saturation magnetization of the sol showed 54.8-58.6 emu/g at 500$800^{\circ} \mathrm{C}$, and the gel showed $52.3-56.8 \mathrm{emu} / \mathrm{g}$ at $600-800^{\circ} \mathrm{C}$. It can be seen that the range where the saturation magnetization of the sol is kept constant was $500^{\circ} \mathrm{C}$ to $800^{\circ} \mathrm{C}$ and of the gel was from $600^{\circ} \mathrm{C}$ to $800^{\circ} \mathrm{C}$. The coercive force of the sol decreased in the range -136 Oe to $-11.4 \mathrm{Oe}$ at $500-800^{\circ} \mathrm{C}$, and the gel decreased in the range $-95 \mathrm{Oe}$ to $-44 \mathrm{Oe}$ at $600-800^{\circ} \mathrm{C}$. It was because the crystal growth and stabilization of the spinel crystal have progressed in these ranges. By analyzing the magnetic properties, it was confirmed that the crystal growth and the crystal stabilization of the sol were lower than the gel by $100^{\circ} \mathrm{C}$.

\section{Conclusion}

NZCF04 nanopowder was fabricated using the sol and the gel. This process was analyzed by TG-DTA analysis, and the nanopowder was analyzed by SEM, XRD, and VSM. As a result, it was found that the temperature of the phase change of the nanopowder prepared by the gel was $100^{\circ} \mathrm{C}$ higher than that of the sol. The spinel crystals were formed at $500^{\circ} \mathrm{C}$ in the sol process and at $600^{\circ} \mathrm{C}$ in the gel process. The size of the crystals was $150 \mathrm{~nm}$ and $90 \mathrm{~nm}$ at $800^{\circ} \mathrm{C}$, respectively. In the sol process, the saturation magnetization was stabilized as 54.8 to $58.6 \mathrm{emu} / \mathrm{g}$ at $500^{\circ} \mathrm{C}$ to $800^{\circ} \mathrm{C}$, and the gel process was stabilized as 52.3 to $56.8 \mathrm{emu} / \mathrm{g}$ at $600^{\circ} \mathrm{C}$ to $800^{\circ} \mathrm{C}$. In this study, the highest 


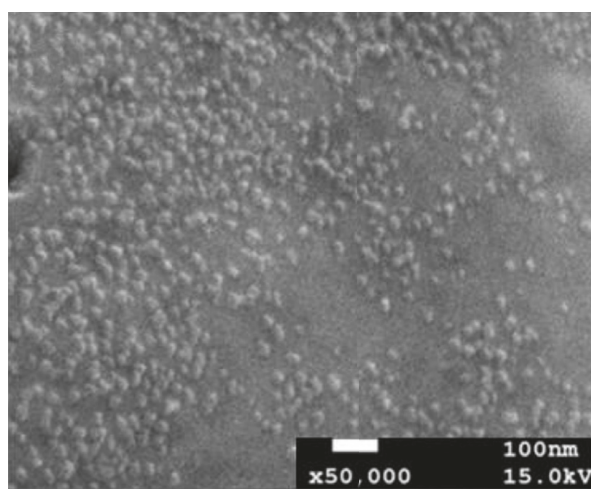

(a)

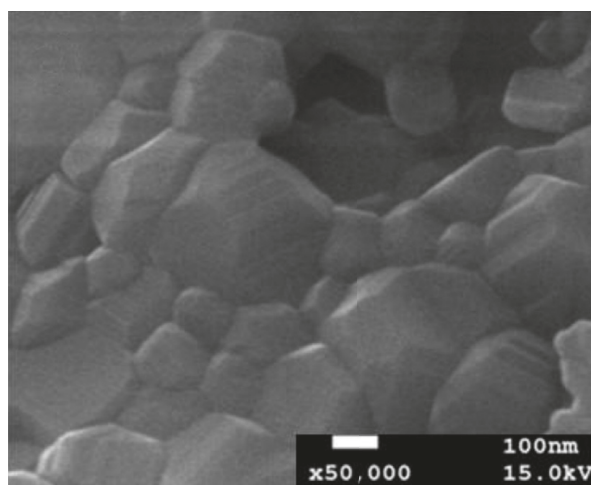

(c)

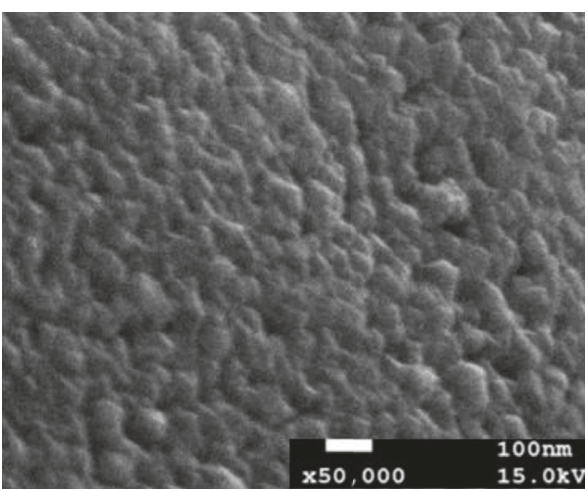

(b)

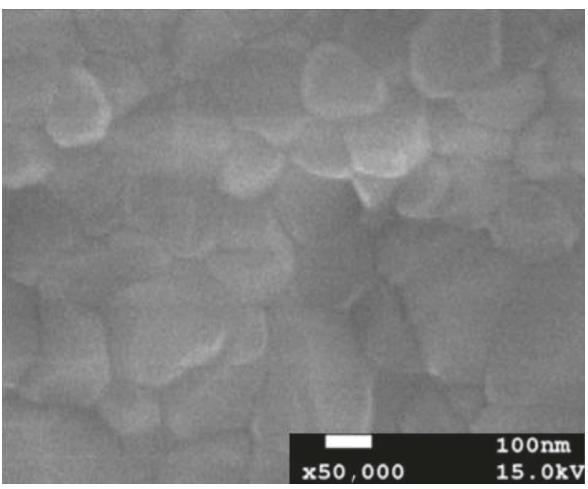

(d)

Figure 4: SEM image $(\times 50,000)$ of (a) $400^{\circ} \mathrm{C}$ sol, (b) $400^{\circ} \mathrm{C}$ gel, (c) $800^{\circ} \mathrm{C}$ sol, and (d) $800^{\circ} \mathrm{C}$ gel.

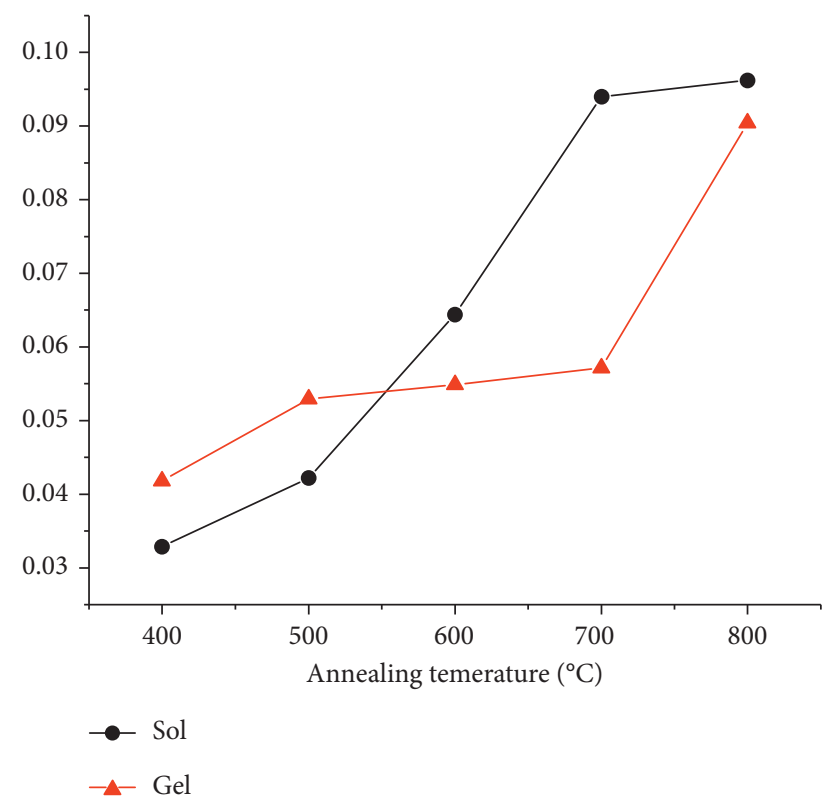

FIGURE 5: Initial permeability of the sol and the gel with annealing temperature.

coercive force of the sol and the gel were -136 Oe and -95 Oe, respectively, also observed at the same annealing temperature as initial temperature of the saturation magnetization stabilization. It was confirmed that the spinel

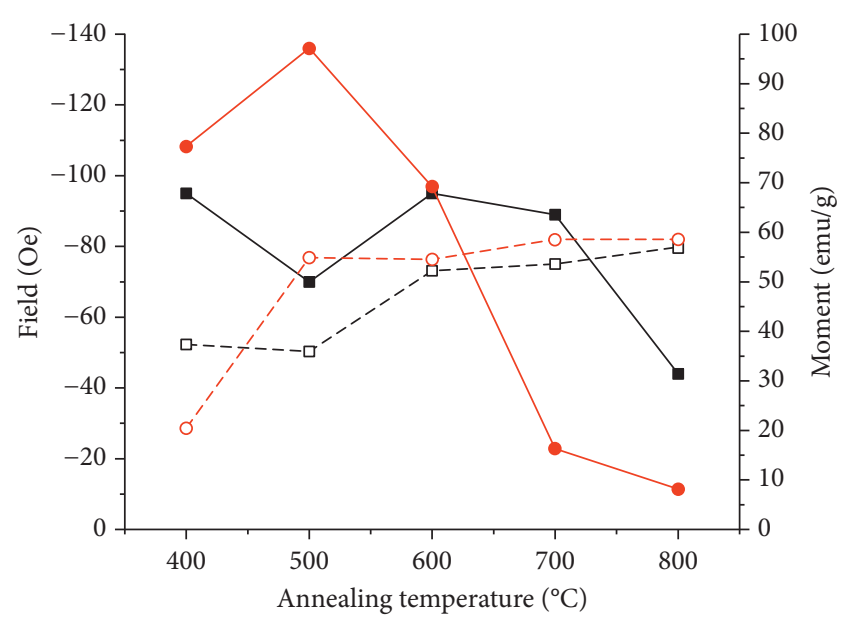

$$
\begin{array}{ll}
\text { Coercive force } & \text { Saturation magnetization } \\
- \text { Gel } & -\square-\text { Gel } \\
\longrightarrow \text { Sol } & -\circ-\text { Sol }
\end{array}
$$

FIGURE 6: Saturation magnetization and coercive force of the sol and the gel with annealing temperature.

crystal was formed at each temperature in the sol and gel processes. In the sol-gel process, the deviation of the annealing temperature of the nanopowder fabricated in the sol process and the gel process was about $100^{\circ} \mathrm{C}$. The soft 
magnetic property exploited wave absorber requires high saturation magnetization value and low coercive force value. In this study, the nanopowder fabricated by the sol-gel process showed sufficient magnetic properties for the wave absorber. It is also expected that the wave absorption frequency exhibits gigahertz range in nanocrystal.

\section{Conflicts of Interest}

The authors declare that there are no conflicts of interest.

\section{References}

[1] F. Qin and C. Brosseau, "A review and analysis of microwave absorption in polymer composites filled with carbonaceous particles," Journal of Applied Physics, vol. 111, no. 6, p. 061201, 2012.

[2] S. Zahi, M. Hashim, and A. R. Daud, "Preparation of $\mathrm{Ni}-\mathrm{Zn}-\mathrm{Cu}$ ferrite particles by sol-gel technique," Material Letters, vol. 60, no. 23, pp. 2803-2806, 2006.

[3] D.-L. Zhao, Q. Lv, and Z.-M. Shen, "Fabrication and microwave absorbing properties of $\mathrm{Ni}-\mathrm{Zn}$ spinel ferrites," Journal of Alloys and Compounds, vol. 480, no. 2, pp. 634-638, 2009.

[4] V. G. Harris, A. Geiler, Y. Chen et al., "Recent advances in processing and applications of microwave ferrites," Journal of Magnetism and Magnetic Materials, vol. 321, no. 14, pp. 2035-2047, 2009.

[5] S. Bierlich and J. Topfer, "Low-temperature firing of substituted M-type hexagonal ferrites for multilayer inductors," IEEE Transactions on Magnetics, vol. 48, no. 4, pp. 1556-1559, 2012.

[6] S. A. Mazen and B. A. Sabrah, "Thermal effect on formation and conduction mechanism of $\mathrm{MnFe}_{2} \mathrm{O}_{4}$," Thermochimica Acta, vol. 105, pp. 1-8, 1986.

[7] M. A. Ahmed, E. Ateia, L. M. Salah, and A. A. El-Gamal, "Structural and electrical studies on $\mathrm{La} 3+$ substituted $\mathrm{Ni}-\mathrm{Zn}$ ferrites," Materials Chemistry and Physics, vol. 92, no. 2-3, pp. 310-321, 2005.

[8] S. Yang and J.-G. Kim, "Magnetic properties of (Nia-Znb)X Cu1-X ferrite nanoparticle fabricated by sol-gel process," Achieve of Metallurgy and Materials, vol. 65, no. 2B, pp. 1197-1200, 2017. 

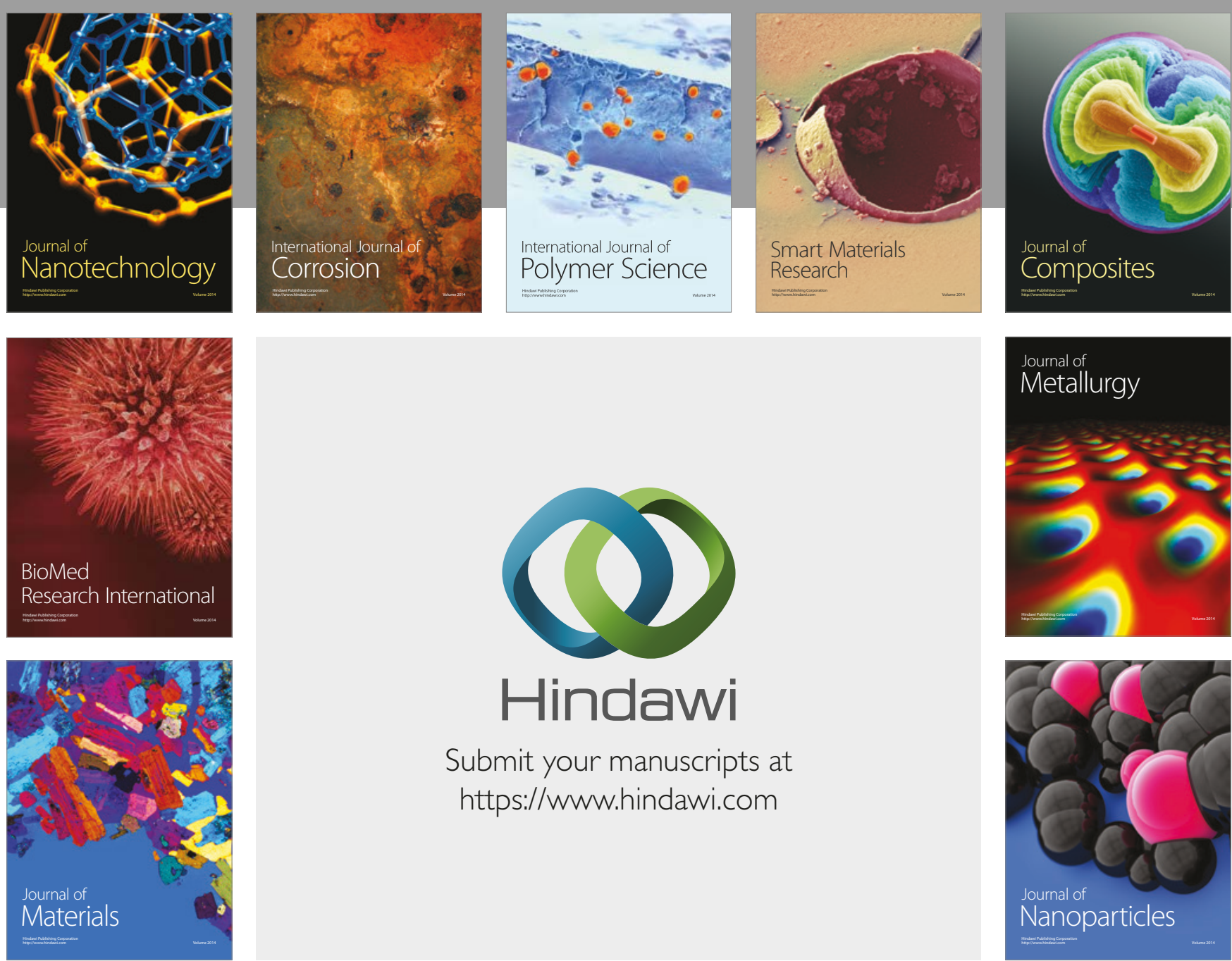

\section{Hindawi}

Submit your manuscripts at

https://www.hindawi.com
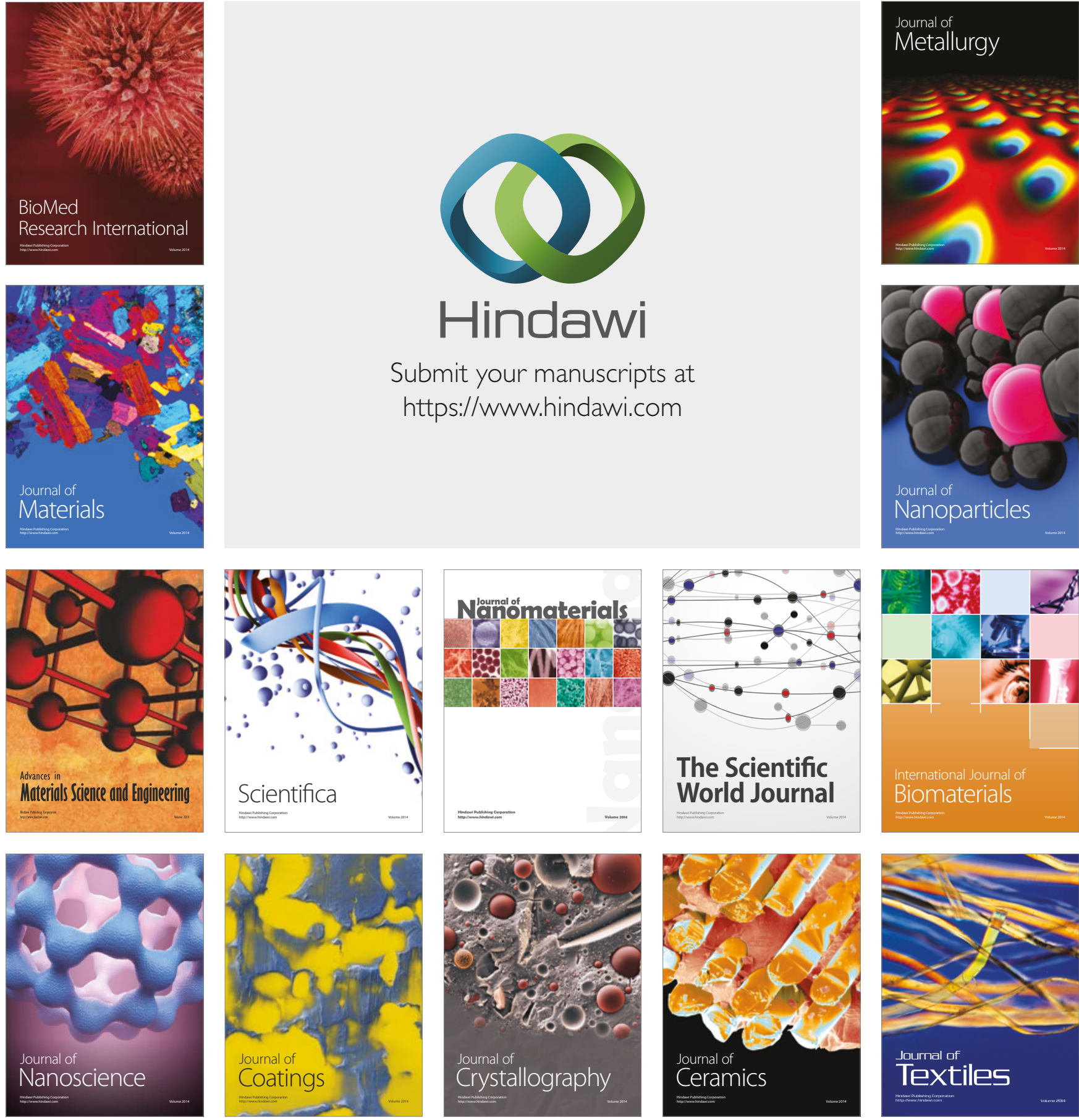

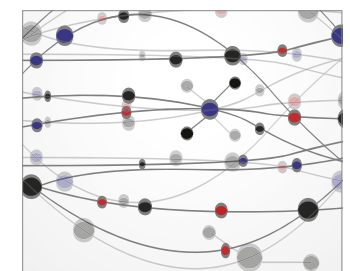

The Scientific World Journal
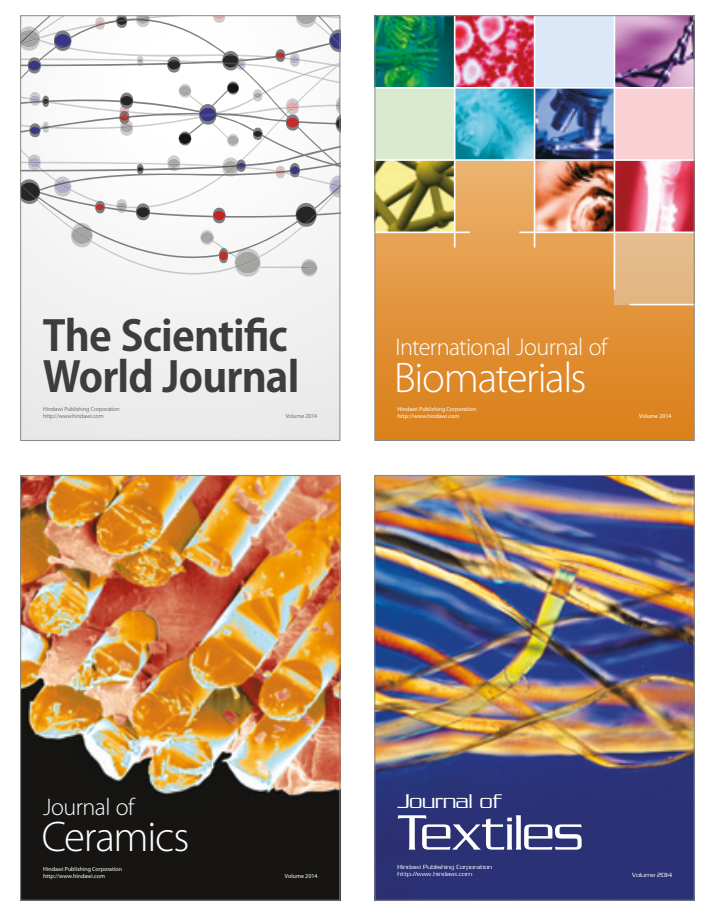